\title{
OPEN Synthesis of mesoporous silica from geothermal water
}

\author{
Yujiro Watanabe ${ }^{1 凶}$, Naoki Amitani ${ }^{1}$, Takushi Yokoyama ${ }^{2}$, Akira Ueda ${ }^{3}$, Minoru Kusakabe ${ }^{3}$, \\ Shigeko Unami ${ }^{3} \&$ Yoshiji Odashima ${ }^{3}$
}

Mesoporous silica was successfully synthesized for the first time using geothermal water from the Onuma Geothermal Power Plant, Akita Prefecture, Japan. Cetyltrimethylammonium bromide (CTAB) was used as an organic template for the synthesis. CTAB with a concentration of $2.4 \times 10^{-4} \mathrm{~mol} / \mathrm{L}$ was reacted for $30 \mathrm{~min}$ with geothermal water at a temperature of $90^{\circ} \mathrm{C}$, which had a total silicic acid concentration of $475 \mathrm{mg} / \mathrm{L}\left(\mathrm{SiO}_{2}\right)$, at $\mathrm{pH} 7.0, \mathrm{pH} 8.2$ (raw water) and $\mathrm{pH}$ 9.0. By calcination of the resulting precipitate at $550^{\circ} \mathrm{C}$, mesoporous silica with a pore size of about $2.8 \mathrm{~nm}$ and a specific surface area of $>800 \mathrm{~m}^{2} / \mathrm{g}$ was formed. The total silicic acid concentration in the solution after formation of the mesoporous precipitates was reduced to $<280 \mathrm{mg} / \mathrm{L}$, indicating efficient recovery of supersaturated silicic acid from geothermal water. The monosilicic acid in geothermal water plays an important role in the formation of mesoporous silica. Production of mesoporous silica by our method will contribute not only to prevention of silica scale formation in the piping systems of geothermal power plants but also to its use as an industrial resource.

In a geothermal power plant, fluids from a deep geothermal reservoir are separated into steam and water. The separated steam is used to rotate a turbine for generation of electricity, whereas the separated water is returned to the underground reservoir through a reduction well. During steam separation, silicic acid is concentrated in the water phase, which becomes supersaturated with respect to the amorphous silica. Polymerization of monosilicic acid followed by reactions between polysilicic and monosilicic acids and between polysilicic acids results in the formation of silica colloids ${ }^{1-3}$. During polymerization, silicic acids precipitate as silica scale inside the pipes of the reinjection wells and the channels in geological formations around the reinjection wells. This results in a reduction of the efficiency of water reinjection, widely known as clogging problems ${ }^{4-8}$. Currently, two methods are in common use to prevent formation of silica scale: (i) $\mathrm{pH}$ adjustment and (ii) high-temperature reinjection. In the $\mathrm{pH}$ adjustment method, the $\mathrm{pH}$ of the geothermal brine is adjusted to around $\mathrm{pH} 6$ to reduce the solubility of amorphous silica and to lower the polymerization rate of silicic acid. In the high-temperature reinjection method, geothermal water is returned to the subsurface at temperatures as high as $150{ }^{\circ} \mathrm{C}$, where the solubility of silica in aqueous solution is high. These methods are unfortunately not fully effective ${ }^{9-15}$. Although some methods to remove silica from supersaturated silicate solution have been proposed ${ }^{16-18}$, they are only partly successful. Thus, it is important to find better and more practical ways for silica removal, followed by its recovery. Additionally, once silica is successfully recovered, its economical use can be envisaged. Mesoporous silica is a useful material in industry and is expected to be applied in a variety of fields, such as catalysts, adsorbents, ion exchangers, optic materials, and solar panels for electric power generation. In general, a cationic surfactant is used to synthesize mesoporous silica, where monosilicic acid is combined with the cationic surfactant. After this process, the combined silicic acids are heated at 80 to $140{ }^{\circ} \mathrm{C}$ for dehydration, condensation, and formation of a silica network, which leads to the formation of mesoporous silica precursors. The precursors are acid-washed and calcined to remove the cationic surfactant. The silica thus obtained shows homogeneous mesoporous characteristics. Two pioneering works have reported that the formation of mesoporous silica takes place by means of a liquid-crystal templating mechanism, in which the silicate material forms inorganic walls between ordered surface micelles ${ }^{19,20}$. Subsequent publications have defined the mechanism as macro-molecular templating, initiated by silicate anions and involving cooperative self-assembly upon mutual attraction between silicate and surfactant ions ${ }^{21-23}$. MCM-41, MCM-48, and MCM-50 from the M41S family of mesoporous silica are synthesized by adding cetyltrimethylammonium bromide (CTAB) as a cationic surfactant ${ }^{24}$. The mixture is matured in an alkaline solution (ca. $\mathrm{pH}$ 11) and processed under hydrothermal conditions at $100{ }^{\circ} \mathrm{C}^{25}$. The mesoporous silica synthesized in this way has a high specific surface area of ca. $1000 \mathrm{~m}^{2} / \mathrm{g}$.

${ }^{1}$ Faculty of Bioscience and Applied Chemistry, Hosei University, 3-7-2 Kajino-cho, Koganei, Tokyo 184-8584, Japan. ${ }^{2}$ Faculty of Science, Kyushu University, Motooka 744, Nishi-ku, Fukuoka 819-0395, Japan. ${ }^{3}$ Faculty of Science, University of Toyama, Toyama, 3190, Gofuku, Toyama 930-8555, Japan. ${ }^{\circledR}$ email: yujiro@hosei.ac.jp 


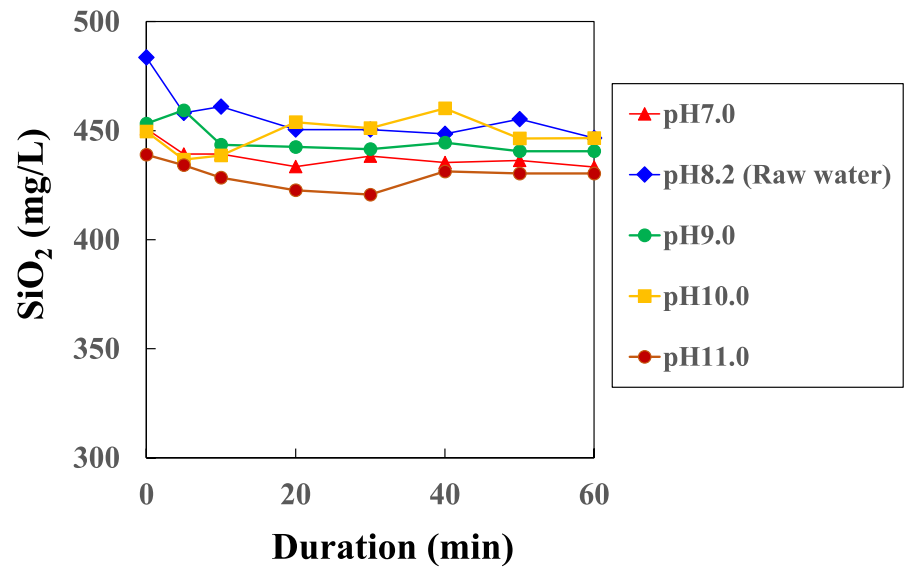

Figure 1. Change over time of monosilicic acid concentration in tested solutions.

We investigated the possibility of direct synthesis of mesoporous silica from supersaturated silicic acid dissolved in high-temperature geothermal water. The use of geothermal water has advantages in that the high water temperature (ca. $100^{\circ} \mathrm{C}$ ) can supply sufficient thermal energy for the synthesis of mesoporous silica, and that monosilicic acid is dissolved at high concentration. To date, there have been many articles on the synthesis of mesoporous silica by adding CTAB to silica scale formed in pipes in geothermal plants ${ }^{26-29}$. There have been no reports on the direct synthesis of mesoporous silica from geothermal fluids. Kitsuki et al..$^{30}$ described the selective removal of polysilicic acid from geothermal water at the Hatchobaru Geothermal Power Plant, Oita, Japan, by using CTAB, and indicated that dissolved silica in geothermal fluids can be effectively recovered. However, their report did not mention the formation of mesoporous silica.

In the present study, we examined conditions under which mesoporous silica can be directly synthesized from geothermal fluids at the Onuma Geothermal Power Plant. Since silicic acid exists as monosilicic acid at the time of sample collection, the formation processes for mesoporous silica with the cationic surfactant can be determined. It is conceivable that a silica network could be formed through dehydration and condensationpolymerization in the presence of CTAB, a process similar to the formation process for polysilicic acid in a high-temperature solution ${ }^{2,31}$. We investigated the change in silicic acid concentration over time when CTAB was added to geothermal water. We also examined the properties of precipitates that were recovered from the geothermal water at different $\mathrm{pH}$ conditions.

\section{Results and discussion}

Variation of monosilicic acid concentrations after sampling of geothermal water. Figure 1 shows the variation with time of the concentrations of monosilicic acids in the Onuma geothermal water at $\mathrm{pH}$ 7 to 11 after sampling. The concentrations of each were similar, and little change with time was observed. More than $420 \mathrm{mg} / \mathrm{L}$ of monosilicic acid was present, indicating that most of the silicic acid was present as monosilicic acid. This suggests that polymerization of silicic acids was slow in the sampled geothermal water. The solubility of silicic acid in water at $90^{\circ} \mathrm{C}$ is $380 \mathrm{mg} / \mathrm{L}^{32}$ and the Onuma water is supersaturated at approximately $95 \mathrm{mg} / \mathrm{L}$. At such a low degree of silica supersaturation, the polymerization rate for monosilicic acid is low. Since monosilicic acid needs to be combined with $\mathrm{CTAB}$ at the initial stage of mesoporous silica formation, the geothermal fluid used in this study is suitable for the formation of mesoporous silica.

Characteristics of silica precipitates and their calcined products. Figure 2 shows X-ray diffraction (XRD) patterns for precipitates obtained $30 \mathrm{~min}$ after addition of CTAB. The precipitates from the solutions with $\mathrm{pH} 7-10$ produced a diffraction peak at a $2 \theta$ value of $1.84^{\circ}$, indicating a $d$ value of $4.80 \mathrm{~nm}$, which is typical for mesoporous silica. The XRD intensity for the samples obtained at pH 7.0, 8.2 and 9.0 was strong. At pH 11.0, however, no diffraction peak around $1.84^{\circ}$ was observed, but a weak peak due to $\mathrm{CaCO}_{3}$ (calcite) appeared at $29^{\circ}$. $\mathrm{CaCO}_{3}$ was formed by the reaction between $\mathrm{Ca}^{2+}$ and $\mathrm{CO}_{3}{ }^{2-}$ ions that were present at low concentrations under alkaline conditions. The precipitates obtained after a $30 \mathrm{~min}$ reaction with CTAB at 30 and 60 minutes after water sampling showed essentially the same XRD patterns as those obtained after a 30 min reaction with CTAB, which was added immediately after water sampling.

Figure 3 shows the XRD patterns for the calcined products that were obtained after the reaction of geothermal water with $\mathrm{CTAB}$ for $30 \mathrm{~min}$. Calcination removed cetyltrimethylammonium ion $\left(\mathrm{CTA}^{+}\right)$templates and induced the formation of fine pores, which was supported by the observation that the sharp XRD peak at around $1.9^{\circ}$, indicating a $d$ value of around $4.65 \mathrm{~nm}$, remained and a peak at $4.2^{\circ}$ was observed, although it was quite broad. This suggests that fine pores were produced. M41S, which is a typical mesoporous silica with one-dimension channels, has two XRD peaks ${ }^{24}$. In the present study, the mesoporous silica obtained also produced two XRD peaks and a peak pattern similar to that for M41S. These results suggested that M41S was directly produced from geothermal water. 


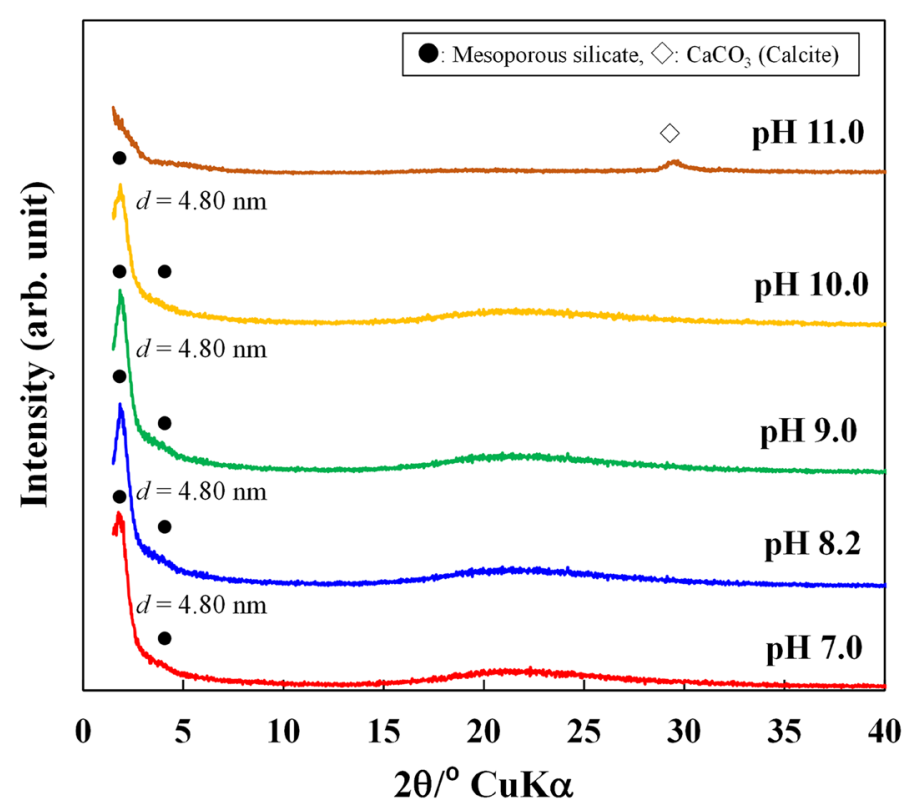

Figure 2. XRD patterns for precipitates.

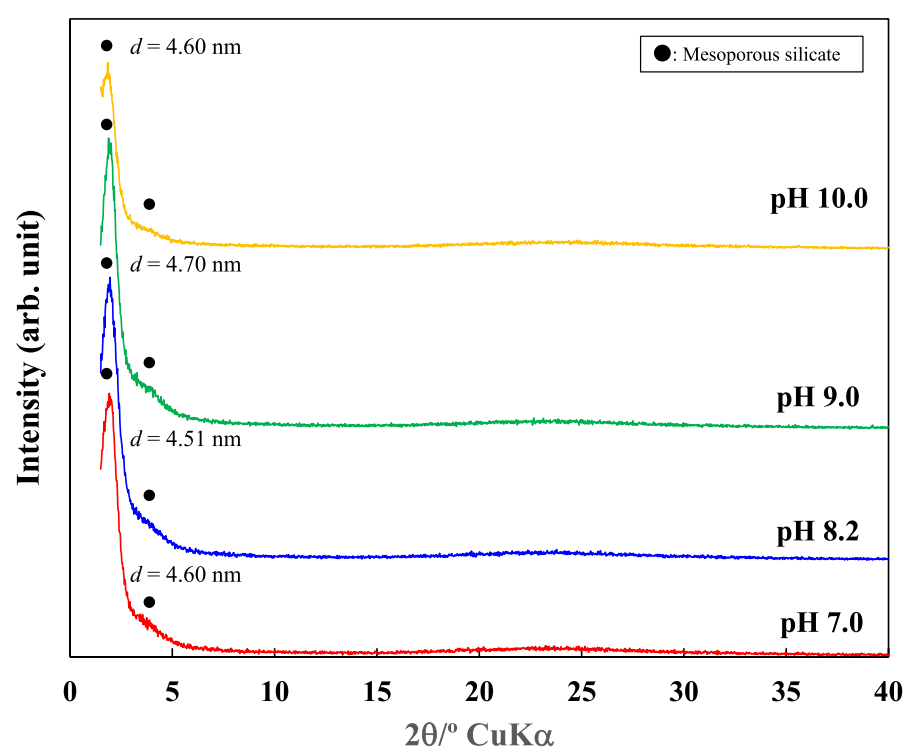

Figure 3. XRD patterns for calcined precipitates.

In general, the M41S family is produced through hydrothermal synthesis of a silica-supersaturated (gelsuspended) solution by adding CTAB at more than its critical micelle concentration ${ }^{25,33}$. We used a CTAB concentration lower than the critical micelle concentration since the geothermal water was dilute with respect to silicic acid. In our case, M41S was formed by adding CTAB at lower concentration. The mechanism suggested macro-molecular templating, initiated by silicate anions and involving cooperative self-assembly upon mutual attraction between silicate and surfactant ions ${ }^{21-23}$. However, the intermediate structures of interacting entities are unknown. Huo et al. ${ }^{23}$ reported that mesoporous silica could be produced from a solution with a low surfactant concentration. This suggests that the interaction between organic and inorganic units is effective in the formation of the mesoporous structure, i.e., the $\mathrm{CTA}^{+}$positive charge attracts monosilicic acid molecules. These organic and inorganic units are combined, self-assembled and polymerized to become a precursor with a mesoporous structure.

Scanning electron microscopy (SEM) images of precipitates from the experiments at pH 7.0, 8.2, 9.0, and 10.0 showed aggregates of amorphous M41S microcrystals, whereas the precipitate from the experiments at $\mathrm{pH} 11.0$ showed rhombohedral-like calcite $\left(\mathrm{CaCO}_{3}\right)$ crystals (Fig. 4). Transmission electron microscopy (TEM) images of calcined precipitates from the experiments at $\mathrm{pH}$ 7.0, 8.2 and 9.0 showed mesoporous structures with pore 

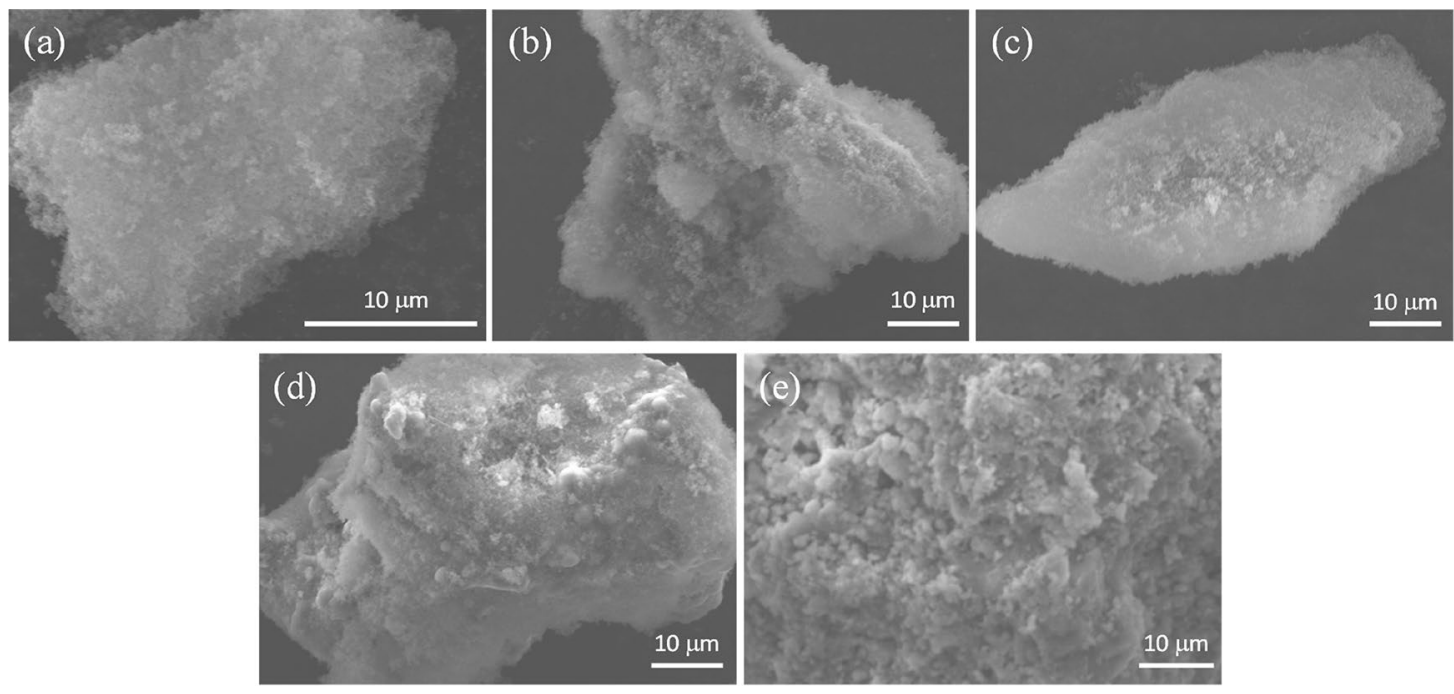

Figure 4. SEM images of precipitates obtained at (a) $\mathrm{pH} 7.0,(\mathbf{b}) \mathrm{pH} 8.2,(\mathbf{c}) \mathrm{pH} 9.0,(\mathbf{d}) \mathrm{pH} 10.0$ and (e) $\mathrm{pH}$ 11.0 .
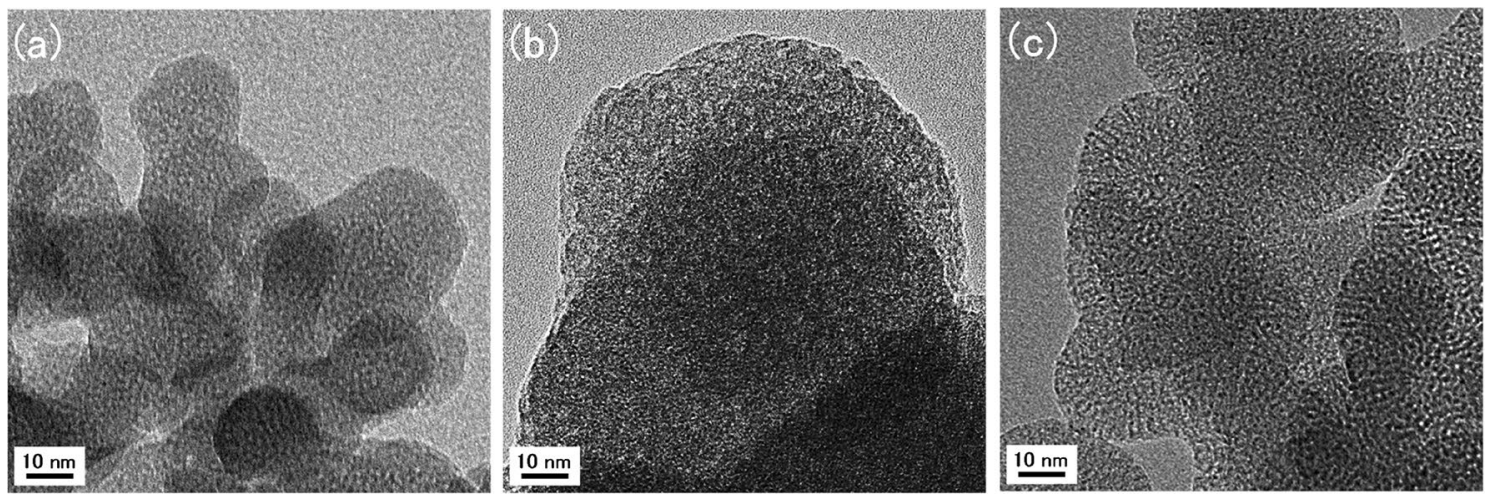

Figure 5. TEM images of calcined precipitates obtained at (a) $\mathrm{pH} 7.0$, (b) $\mathrm{pH} 8.2$ and (c) $\mathrm{pH} 9.0$.

\begin{tabular}{|l|l|l|l|}
\hline $\mathbf{p H}$ & Surface area $\left(\mathbf{m}^{2} / \mathbf{g}\right)$ & Pore diameter $(\mathbf{n m})$ & Pore volume $\left(\mathbf{c m}^{3} / \mathbf{g}\right)$ \\
\hline 7.0 & 834 & 2.8 & 0.6 \\
\hline 8.2 & 814 & 2.8 & 0.6 \\
\hline 9.0 & 919 & 2.8 & 0.7 \\
\hline 10.0 & 551 & 2.6 & 0.4 \\
\hline
\end{tabular}

Table 1. Surface areas, pore diameters and pore volumes for mesoporous silica obtained in different $\mathrm{pH}$ solutions.

sizes of 2-3 nm (Fig. 5). The distance between each pore (wall thickness) was $1-2 \mathrm{~nm}$. The M41S does not have a hexagonal structure, which is a typical characteristic of MCM-41. The structure is unknown ${ }^{24}$. The specific surface areas, mean pore diameters and pore volumes for the calcined precipitates formed at $\mathrm{pH}$ 7-10 are shown in Table 1. These values were obtained from isotherms of nitrogen adsorption and desorption experiments. Barrett-Joyner-Halenda (BJH) plots for pore sizes of less than $50 \mathrm{~nm}$ were calculated from the isotherms (Fig. 6). The isotherms were typical of mesoporous materials. The specific surface areas of the precipitates obtained from the $\mathrm{pH} 7.0,8.2$, and 9.0 experiments were greater than $800 \mathrm{~m}^{2} / \mathrm{g}$. Table 2 shows the results of an energy-dispersive $\mathrm{X}$-ray spectroscopy (EDX) analysis (excluding carbon) of the precipitates obtained under different $\mathrm{pH}$ conditions. The precipitates from the $\mathrm{pH}$ 7-10 runs contained $\mathrm{Si}$ and $\mathrm{O}$ as main components, suggesting that the precipitates were composed of $\mathrm{SiO}_{2}$. Although a minute amount of $\mathrm{Al}$ substituted in $\mathrm{Si}$ sites was detected, other ions were not present. This suggested the formation of mesoporous silica of high purity. The precipitates from a $\mathrm{pH} 11.0$ run contained an appreciable amount of $\mathrm{Ca}$ ions, implying $\mathrm{CaCO}_{3}$ formation, consistent with the XRD and SEM analysis results. Mesoporous silica is generally synthesized under highly alkaline conditions where reactions 

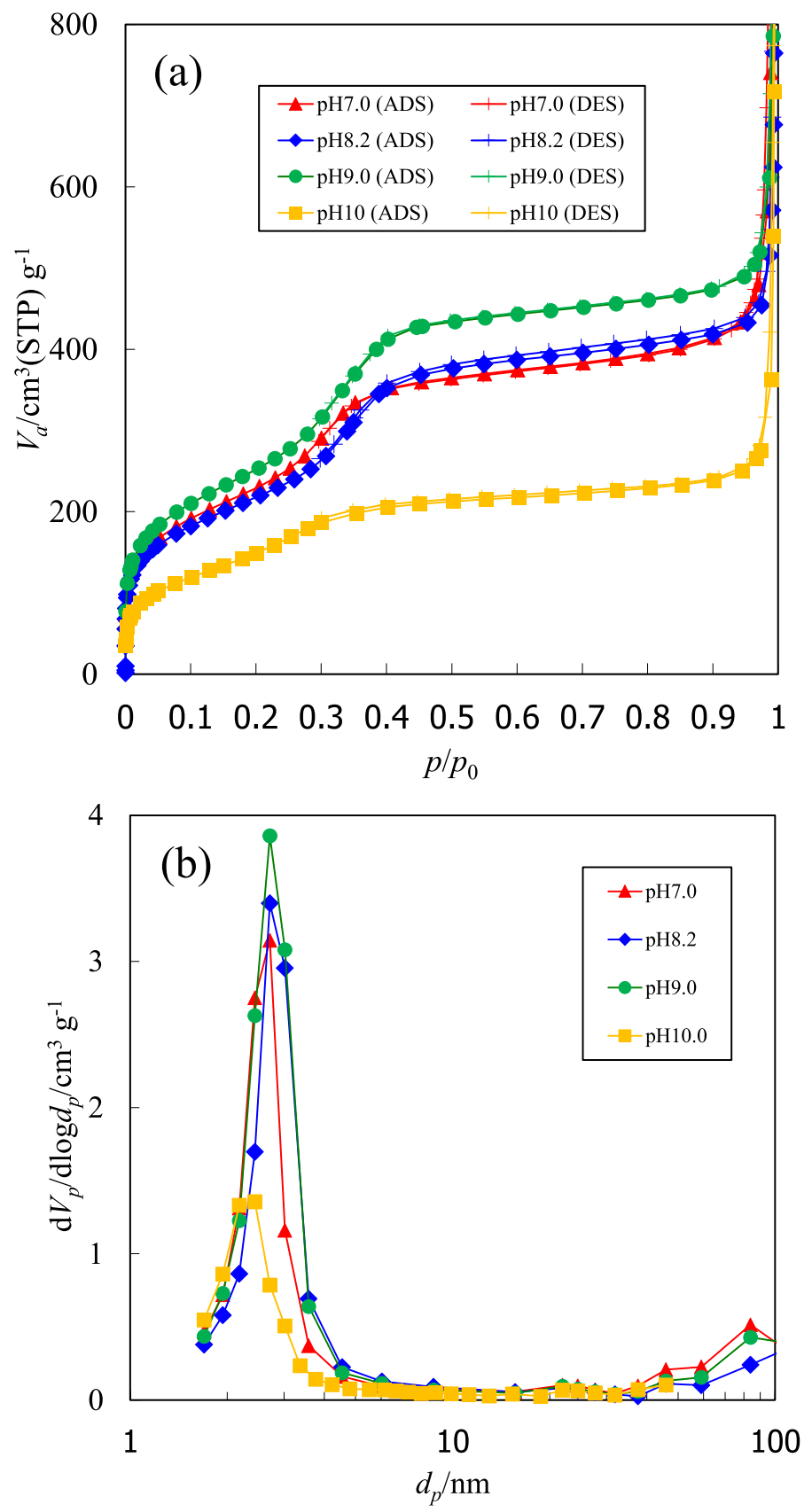

Figure 6. (a) Nitrogen adsorption/desorption isotherms for calcined precipitates, and (b) BJH plots for pore size distributions.

\begin{tabular}{|l|l|l|c|l|l|l|}
\hline $\mathbf{p H}$ & $\mathrm{SiO}_{2}$ & $\mathrm{Al}_{2} \mathbf{O}_{3}$ & $\mathbf{C a}$ & $\mathbf{N a}$ & $\mathbf{K}$ & $\mathbf{C l}$ \\
\hline 7.0 & 46.2 & 2.23 & 0.00 & 0.02 & 0.00 & 0.23 \\
\hline 8.2 & 44.5 & 2.25 & 0.08 & 0.13 & 0.15 & 0.27 \\
\hline 9.0 & 48.9 & 2.29 & 0.02 & 0.00 & 0.03 & 0.13 \\
\hline 10.0 & 45.8 & 3.78 & 0.04 & 0.01 & 0.02 & 0.07 \\
\hline 11.0 & 35.5 & 1.11 & 16.61 & 0.65 & 0.05 & 0.30 \\
\hline
\end{tabular}

Table 2. Chemical composition (wt\%) of mesoporous silica obtained in different $\mathrm{pH}$ solutions. 


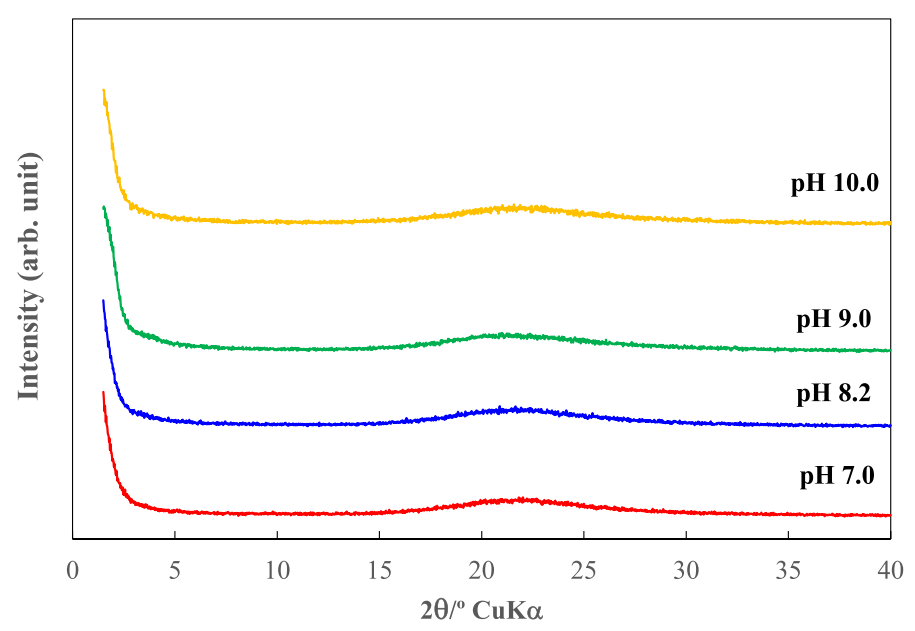

Figure 7. XRD patterns for precipitates prepared in the laboratory.

between the monosilicic acid and CTAB surfactant are promoted ${ }^{25}$. It has been suggested that this may inhibit the reaction between $\mathrm{CTA}^{+}$and monosilicic acid. The arsenic concentration in the precipitates was below the detection limit $(0.01 \%)$. This is favorable for production of mesoporous silica on an industrial basis.

From the foregoing discussions, we can conclude that the synthesis of mesoporous silica is best achieved under neutral to weakly alkaline conditions, e.g., at $\mathrm{pH}$ 7-9, where silicic acid exists mainly as monosilicic acid. In addition, no impurities such as calcite and arsenic acid were incorporated under $\mathrm{pH}$ conditions of 7 to 9.

Formation process for mesoporous silica in geothermal water. Cetyltrimethylammonium ions $\left(\mathrm{CTA}^{+}\right)$combine preferentially with dissociated silanol groups $(-\mathrm{Si}-\mathrm{O}-)$ on the surface of polysilicic acid but not with monosilicic acid ${ }^{30}$. In our experiments, however, the CTAB concentration was high and monosilicate ions were attracted to the positive charges on the surface of the $\mathrm{CTA}^{+}$. In the laboratory, the same experiment was conducted using geothermal water ( $\mathrm{pH} 7-10)$ that was more than 4 weeks old. The concentration of monosilicic acid in the geothermal water was less than $150 \mathrm{mg} / \mathrm{L}$, and most of the silicic acid was present as polysilicic acid. CTAB was added to the geothermal water at a concentration of $2.4 \times 10^{-4} \mathrm{~mol} / \mathrm{L}$ and kept in a water bath at $90{ }^{\circ} \mathrm{C}$ for $30 \mathrm{~min}$. The XRD patterns of the precipitates showed no diffraction peaks attributed to mesoporous silica (Fig. 7). It is considered that the formation of mesoporous structure was inhibited by the large amount of polysilicic acid in the geothermal water. The polysilicic acid may have condensed to form amorphous silica in this condition. Thus, it is considered that the combination of monosilicic acid with $\mathrm{CTA}^{+}$plays an important role in the formation of a mesoporous structure. We have clearly shown that mesoporous silica can be synthesized in the presence of a small amount of CTAB in geothermal water containing a large proportion of monosilicic acid at $\mathrm{pH} 7-9$.

Effect of CTAB addition on the change in silicic acid concentration. The change with time of the total silicic acid concentration in geothermal waters $30 \mathrm{~min}$ after the addition of CTAB at $\mathrm{pH} 7-11$ is illustrated in Fig. 8. The silicic acid concentration was most reduced at $\mathrm{pH} 7.0$, and it increased with increasing $\mathrm{pH}$. At $\mathrm{pH}$ 10.0 and 11.0, the reduction of the silicic acid concentration was small compared to the initial total silicic acid concentration of the raw geothermal water $(475 \mathrm{mg} / \mathrm{L}$ at $\mathrm{pH} 8.2)$, indicating that a large proportion of silicic acid remained unreacted. At lower $\mathrm{pH}$, mesoporous silica having a high specific surface area was synthesized. The total silicic acid was reduced by $229 \mathrm{mg} / \mathrm{L}$ compared to the initial total value, indicating that the recovery rate for the total silicic acid was $48.2 \%$. We were able to recover more silica than the saturated concentration of $380 \mathrm{mg} / \mathrm{L}^{32}$, the solubility of amorphous silica at $90^{\circ} \mathrm{C}$. The excess silica recovered from the tested thermal water amounted to $95 \mathrm{mg} / \mathrm{L}$. Our results show that high-quality mesoporous silica can be synthesized from geothermal waters, and that our technique can be applied to the reduction of silica scale at geothermal power plants. The reaction with $\mathrm{CTAB}$ can also remove $\mathrm{Al}$ from geothermal waters, thus contributing to the simultaneous removal of $\mathrm{Al}$ and silica, which prevents scale formation in piping systems ${ }^{34,35}$.

\section{Conclusions}

We succeeded in the first direct synthesis of mesoporous silica using thermal water from the Onuma Geothermal Power Plant, Akita, Japan. Mesoporous silica was synthesized by adding CTAB at a concentration of $2.4 \times 10^{-4} \mathrm{~mol} / \mathrm{L}$ to the water at $90^{\circ} \mathrm{C}$, waiting for $30 \mathrm{~min}$ for completion of the reaction, filtering and drying the precipitates, and then calcinating at $550^{\circ} \mathrm{C}$. The mesoporous silica obtained from $\mathrm{pH} 7.0,8.2$, and 9.0 geothermal water had a high specific surface area of $>800 \mathrm{~m}^{2} / \mathrm{g}$. It is expected that excess dissolved monosilicic acid can be removed and recovered as mesoporous silica. Thus, scale formation can be prevented. Our new technique demonstrates that mesoporous silica can be directly produced from geothermal water, leading to prevention of silica scale and to the production of economically valuable materials. 


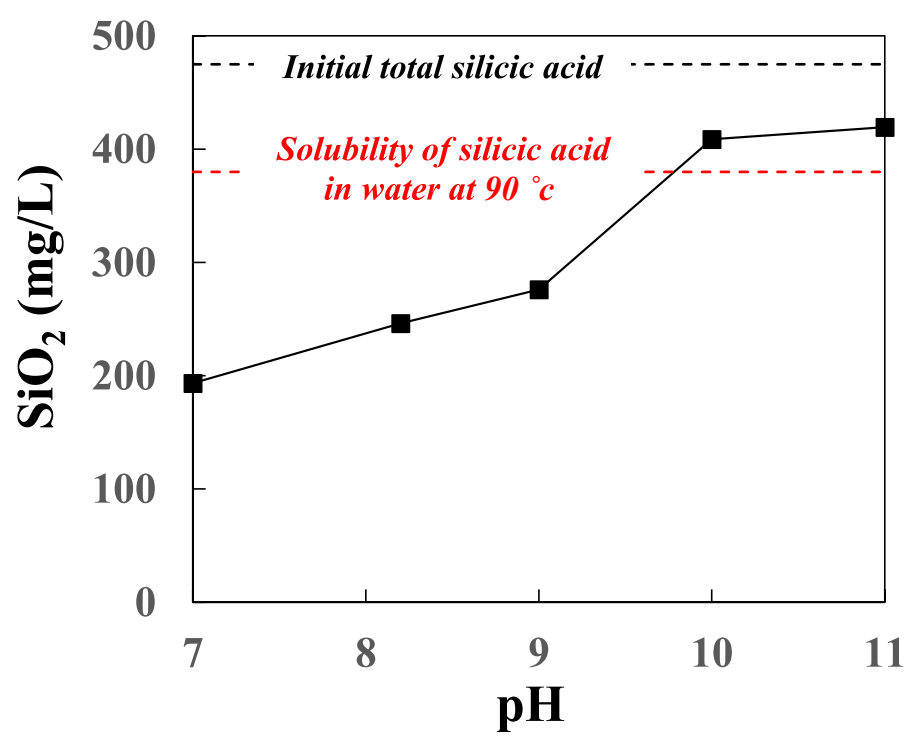

Figure 8. Total silicic acid concentration 30 min after CTAB addition.

\begin{tabular}{|l|l|}
\hline Dissolved species & Concentration $(\mathbf{m g} / \mathbf{L})$ \\
\hline $\mathrm{Na}^{+}$ & 406 \\
\hline $\mathrm{K}^{+}$ & 41.2 \\
\hline $\mathrm{Ca}^{2+}$ & 15.5 \\
\hline $\mathrm{Mg}^{2+}$ & $<0.01$ \\
\hline $\mathrm{Fe}^{2+}$ & $<0.01$ \\
\hline $\mathrm{Al}^{3+}$ & 0.8 \\
\hline $\mathrm{Cl}^{-}$ & 431 \\
\hline $\mathrm{SO}_{4}^{2-}$ & 225 \\
\hline $\mathrm{HCO}_{3}^{-}$ & 86 \\
\hline $\mathrm{SiO}_{2}$ & 475 \\
\hline $\mathrm{pH}$ & 8.2 \\
\hline $\mathrm{EC}(\mathrm{mS} / \mathrm{m})$ & 201 \\
\hline
\end{tabular}

Table 3. Chemical composition of geothermal water used to synthesize mesoporous silica at well O-12R, Onuma geothermal power plant. Data supplied by Mitsubishi Material Co. Ltd. Date of sampling: 2020/7/21.

\section{Methods}

Sampling and chemistry of thermal water. The experiments were performed between October 29th and November 1st, 2020, at the Onuma Geothermal Power Plant operated by Mitsubishi Materials Corporation, Akita Prefecture, Japan. The two-phase thermal water from the production well O-12R was separated into steam and water using a separator. The chemical composition of the water phase is shown in Table 3 . The water was relatively dilute with $\mathrm{pH} 8.2,\left[\mathrm{Na}^{+}\right]=406 \mathrm{mg} / \mathrm{L},\left[\mathrm{K}^{+}\right]=41 \mathrm{mg} / \mathrm{L}$, and $\left[\mathrm{Ca}^{2+}\right]=15.5 \mathrm{mg} / \mathrm{L}$. The total $\mathrm{SiO}_{2}$ concentration was $475 \mathrm{mg} / \mathrm{L}$. The temperature of the water was $90^{\circ} \mathrm{C}$ at the time of sample collection. Since the solubility of amorphous silica at $90^{\circ} \mathrm{C}$ is $380 \mathrm{mg} / \mathrm{L}^{32}, \mathrm{SiO}_{2}$ existed in excess by $95 \mathrm{mg} / \mathrm{L}$. The $\mathrm{Al}^{3+}$ concentration in the sample solution was $0.8 \mathrm{mg} / \mathrm{L}$.

Synthesis of mesoporous silica from geothermal water. Twenty liters of sample water ( $\mathrm{pH} 8.2)$ were collected in a polyethylene container. CTAB was added to the geothermal water to a concentration of $2.4 \times 10^{-4} \mathrm{~mol} / \mathrm{L}$. The water was kept in a water bath at $90{ }^{\circ} \mathrm{C}$ for $30 \mathrm{~min}$. The CTAB concentration was higher than $1.0 \times 10^{-4} \mathrm{~mol} / \mathrm{L}$, which was sufficient to react with $\mathrm{Si}-\mathrm{O}$ units that existed on the surface of polysilicic acid $^{26}$. Similar experiments were performed at $\mathrm{pH} 7.0,9.0,10.0$, and 11.0, adjusted using either $\mathrm{H}_{2} \mathrm{SO}_{4}$ or $\mathrm{NaOH}$ solutions. Thirty minutes later, the precipitates were filtered through filter paper and dried at room temperature using a vacuum drying oven. In the laboratory, the same experiment was carried out using geothermal water ( $\mathrm{pH} 7-10)$ that was more than 4 weeks old. CTAB was added to this geothermal water at a concentration of $2.4 \times 10^{-4} \mathrm{~mol} / \mathrm{L}$. The water was kept in a water bath at $90{ }^{\circ} \mathrm{C}$ for $30 \mathrm{~min}$. For raw geothermal water $(\mathrm{pH} 8.2)$, $\mathrm{CTAB}$ was added 30 or $60 \mathrm{~min}$ later. The reaction time was $30 \mathrm{~min}$. 
Analytical procedures. Analysis of mono- and total silicic acid concentrations. $850 \mathrm{~mL}$ of untreated geothermal water was placed in a $1 \mathrm{~L}$ Teflon beaker to which $3 \mathrm{~mL}$ sulfuric acid or $\mathrm{NaOH}$ solution had been added to adjust the $\mathrm{pH}$ of the solution to $7.0,9.0,10.0$ or $11.0( \pm 0.2)$. The solution was kept at $90^{\circ} \mathrm{C}$ for $30 \mathrm{~min}$. An aliquot of the solution was sampled at intervals of 5 to $10 \mathrm{~min}$ and filtered through a $0.22 \mu \mathrm{m}$ membrane filter. The monosilicic acid concentration was measured spectrophotometrically (UV-1280; Shimadzu) at $385 \mathrm{~nm}$ based on the formation of a yellow molybdosilicic acid complex. The total silicic acid concentration was obtained after making the solution alkaline by adding $\mathrm{NaHCO}_{3}$ powder and heating. This process decomposed polysilicic acid to monosilicic acid for which the concentration was determined spectrophotometrically. The analytical precision was $\pm 5 \%$. The total silicic acid concentration after $30 \mathrm{~min}$ reaction with CTAB was determined similarly using an ICP emission spectrometer (ICPE9800; Shimadzu).

Characterization of silica precipitates. The dried silica precipitates were checked for their crystallinity using powder XRD (Ultima IV; Rigaku) with monochromatized CuKa radiation operated at $40 \mathrm{kV}$ and $30 \mathrm{~mA}$, for their appearance using TEM (JEM-2000FX; JEOL) operated at $200 \mathrm{kV}$ and SEM (JSM-6700; JEOL) operated at $15 \mathrm{kV}$, and for their chemical compositions using EDX (EMAX; Horiba). CTAB was removed by gradual heating of the precipitates in an electric furnace to $550{ }^{\circ} \mathrm{C}$ (temperature was raised at a rate of $10^{\circ} \mathrm{C} / \mathrm{min}$ ) for $1 \mathrm{~h}$ under nitrogen atmosphere. The precipitates were calcined at $550^{\circ} \mathrm{C}$ in air for an additional $1 \mathrm{~h}$. The sample thus obtained was analyzed with XRD. The specific surface areas, pore diameters and pore volume were measured using a nitrogen adsorption and desorption apparatus (BELSORP MINI X; MicrotracBEL) after removal of physically adsorbed water at $200{ }^{\circ} \mathrm{C}$ for $6 \mathrm{~h}$ in vacuum. These values were calculated from the nitrogen adsorption and desorption isotherms using the Brunauer-Emmett-Teller (BET) method and the BJH method ${ }^{36}$.

Received: 20 August 2021; Accepted: 18 November 2021

Published online: 10 December 2021

\section{References}

1. Iler, R. K. Removal of silica from water. In The Chemistry of Silica: Solubility, Polymerization, Colloid and Surface Properties, and Biochemistry (ed. Iler, R. K.) 78-83 (Wiley-Interscience, 1979).

2. Yokoyama, T., Shimada, K., Shimono, T. \& Tarutani, T. Polymerization of silicic acid in geothermal water. Chinetsu (Geochem. Geotherm. Dev.) 20, 319-324 (1983).

3. Tamura, R. et al. In situ observations of silica nanoparticle growth in geothermal brine at the Sumikawa plant, Japan, by dynamic light scattering. Geothermics 77, 304-312 (2019).

4. Itoi, R. et al. Study on decrease of reservoir permeability due to deposition of silica dissolved in reinjection water. J. Geotherm. Res. Soc. Jpn. 8, 229-241 (1986).

5. Mroczeck, E. K., White, S. P. \& Graham, D. J. Deposition of amorphous silica in porous packed beds-predicting the lifetime of reinjection aquifers. Geothermics 29, 737-757 (2000).

6. Gunnarsson, I. \& Arnorsson, S. Impact of silica scaling on the efficiency of heat extraction from high-temperature geothermal fluids. Geothermics 34, 320-329 (2005).

7. Yanaze, T., Yoo, S.-Y., Marumo, K. \& Ueda, A. Prediction of permeability reduction due to silica scale deposition with a geochemical clogging model at Sumikawa geothermal power plant. Geothermics 79, 114-128 (2019).

8. Zarrouk, S. J. \& Moon, H. Efficiency of geothermal plants: A worldwide review. Geothermics 51, 142-153 (2014).

9. Henley, R. W. pH and silica scaling control in geothermal field development. Geothermics 12, 307-321 (1983).

10. Brown, K.L. \& McDowell, G.D. pH control of silica scaling. In Proc. 5th New Zealand Geothermal Workshop, 157-161 (1983)

11. Gallup, D. L. Brine pH modification scale control technology. Geotherm. Resour. Council Trans. 20, 749-755 (1996).

12. Gallup, D. L. The interaction of silicic acid with sulfurous acid scale inhibitor. Geotherm. Resour. Council Trans. 21, 49-53 (1997).

13. Hirowatari, K. Scale prevention method by brine acidification with biochemical reactors. Geothermics 25, 259-270 (1996).

14. Addison, S. J. et al. Brine silica management at Mighty River power, New Zealand. In Proc. World Geothermal Congress 2015 , 19-25 (2015).

15. Ueda, A., Kato, H., Miyauchi, H. \& Kato, K. Investigation of $\mathrm{pH}$ control method to avoid silica scaling in the Sumikawa geothermal field. J. Geotherm. Soc. Jpn. 25, 163-177 (2003).

16. Yonezu, K. et al. Two viewpoints for removal of silicic acid from geothermal water to prevent silica scaling. In Proc. 41st New Zealand Geothermal Workshop, Auckland, New Zealand, 30 (2019).

17. Ueda, A. et al. Recovery of silica from the Sumikawa geothermal fluids by addition of cationic reagents. J. Geotherm. Soc. Jpn. 22, 249-258 (2000).

18. Hanajima, E. \& Ueda, A. Recovery of oversaturated silica from Takigami and Sumikawa geothermal brines with cationic polymer flocculants to prevent silica scale deposition. Geothermics 70, 271-280 (2017).

19. Kresge, C. J. et al. Ordered mesoporous molecular sieves synthesized by a liquid-crystal template mechanism. Nature 359, 710-712 (1992).

20. Beck, J. S. et al. A new family of mesoporous molecular sieves prepared with liquid crystal templates. J. Am. Chem. Soc. 114, 10834-10843 (1992).

21. Monnier, A. et al. Cooperative formation of inorganic-organic interfaces in the synthesis of silicate mesostructures. Science 261, 1299-1303 (1993).

22. Beck, J. S. et al. Molecular or supramolecular templating: Defining the role of surfactant chemistry in the formation of microporous and mesoporous molecular sieves. Chem. Mater. 6, 1816-1821 (1994).

23. Huo, Q. et al. Organization of organic molecules with inorganic molecular species into nanocomposite biphase arrays. Chem. Mater. 6, 1176-1191 (1994).

24. Roth, W. J. \& Vartuli, J. C. Zeolites and ordered mesoporous materials: Progress and prospects. In Studies in Surface Science and Catalysis 157 (eds Ceika, J. \& van Bekkum, H.) 91-110 (Elsevier Science, 2005).

25. Edler, K. J. et al. Small angle X-ray scattering from MCM-41 and its synthesis gels: optimization of the synthesis parameters. Colloids Surf. A 102, 213-230 (1995).

26. Bai, S., Yang, F., Wang, Y. \& Wang, K. Removal and recovery of silica source from geothermal water recycling system by calcium nitrate and sodium hydroxide. Adv. Mater. Res. 516-517, 380-383 (2012).

27. Bagshaw, A. A. \& Testa, F. Wairakei geothermal silica, a low cost reagent for the synthesis of mesostructured M41S alumino-silicate molecular sieves. Micro. Meso. Mater. 39, 67-75 (2000). 
28. Silviana, S., Purbasari, A., Siregar, A., Rochyati, A. F. \& Papra, T. Synthesis of mesoporous silica derived from geothermal waste with cetyl trimethyl ammonium bromide (CTAB) surfactant as drug delivery carrier. AIP Conf. Proc. 2296, 020083 (2020).

29. Bai, S. \& Naren, G. Synthesis of mesoporous silica from geothermal water recycling system. In 2011 International Symposium on Water Resource and Environmental Protection, 1455-1458 (2011).

30. Kitsuki, H. et al. Precipitation of silicic acid from geothermal water by addition of cethyltrimethylammonium bromide. J. Geotherm. Soc. Jpn. 8, 1-14 (1986).

31. Rothbaum, H. P. et al. Effect of silica polymerization and pH on geothermal scaling. Geothermics 8, 1-20 (1979).

32. Fournier, R. O. Chemical geothermometers and mixing model for geothermal systems. Geothermics 5, 41-50 (1977).

33. Watanabe, Y. et al. Adsorption behavior of copper ions on chemically modified MCM-41. J. Ion Exchange 21, 282-287 (2010).

34. Yokoyama, T., Takahashi, Y. \& Tarutani, T. Retarding and accelerating effects of aluminum on the growth of polysilicic acid particles. J. Colloid Interface Sci. 141, 559-563 (1991).

35. Yokoyama, T., Itoi, R. \& Uchida, A. Chemistry of silica scales at the geothermal power stations. Chinetsu (Geochem. Geotherm. Dev.) 39, 161-190 (2002).

36. Barrett, E. P., Joyner, L. G. \& Halenda, P. P. The determination of pore volume and area distribution in porous substances. I. Computations from nitrogen isotherms. J. Am. Chem. Soc. 73, 373-380 (1951).

\title{
Acknowledgements
}

The authors wish to thank the members of Mitsubishi Materials Corporation for their support during the fieldwork and for providing us with the chemical composition of the geothermal water used in the experiments. We are indebted to Ms. H. Tokimori, Hosei University, for her kind assistance with TEM observations. We would like to thank the editor and the anonymous reviewers for their critical, kind, and constructive comments that have helped us tremendously to improve the manuscript.

\section{Author contributions}

Y.W. wrote the manuscript and performed the experiments. N.A., T.Y., A.U., M.K., S.U. and Y.O. supported the experiments and preparation of the manuscript. Y.W. acted as the corresponding author, supervising the overall research and the manuscript preparation.

\section{Competing interests}

The authors declare no competing interests.

\section{Additional information}

Correspondence and requests for materials should be addressed to Y.W.

Reprints and permissions information is available at www.nature.com/reprints.

Publisher's note Springer Nature remains neutral with regard to jurisdictional claims in published maps and institutional affiliations.

\begin{abstract}
(c) (i) Open Access This article is licensed under a Creative Commons Attribution 4.0 International License, which permits use, sharing, adaptation, distribution and reproduction in any medium or format, as long as you give appropriate credit to the original author(s) and the source, provide a link to the Creative Commons licence, and indicate if changes were made. The images or other third party material in this article are included in the article's Creative Commons licence, unless indicated otherwise in a credit line to the material. If material is not included in the article's Creative Commons licence and your intended use is not permitted by statutory regulation or exceeds the permitted use, you will need to obtain permission directly from the copyright holder. To view a copy of this licence, visit http://creativecommons.org/licenses/by/4.0/.
\end{abstract}

(c) The Author(s) 2021 